\title{
Halloysite Nanotubes Filled Natural Rubber Composites: Functionality, Crystallinity and Thermal Studies
}

\author{
Nabil Hayeemasae ${ }^{1^{*}}$, Kamaruddin Waesateh ${ }^{1}$, Abdulhakim Masa ${ }^{2}$ and \\ Hanafi Ismail ${ }^{3}$
}

\begin{abstract}
${ }^{1}$ Department of Rubber Technology and Polymer Science, Faculty of Science and Technology, Prince of Songkla University, Pattani Campus, Thailand ${ }^{2}$ Sino-Thai International Rubber College, Prince of Songkla University, Thailand

${ }^{3}$ School of Materials and Mineral Resources Engineering, Universiti Sains Malaysia, Engineering Campus, 14300 Nibong Tebal, Pulau Pinang, Malaysia
\end{abstract}

${ }^{*}$ Corresponding author: nabil.h@psu.ac.th

Published online: 30 April 2019

To cite this article: Nabil Hayeemasae, Kamaruddin Waesateh, Abdulhakim Masa and Hanafi Ismail (2019). Halloysite nanotubes filled natural rubber composites: Functionality, crystallinity and thermal studies. Journal of Engineering Science, 15, 1-10, https://doi. org/10.21315/jes2019.15.1.

To link to this article: https://doi.org/10.21315/jes2019.15.1

\begin{abstract}
In this article, low loading of Halloysite Nanotube (HNT) was used as filler for natural rubber (NR) composites where it was used at 0-10 phr. The change of functionalities and crystalline structure were investigated by means of Fourier transform infrared (FTIR) and X-ray diffraction (XRD). The performance of the composites was further monitored through the thermogravimetric analysis. The band of Al-OH vibration shifted from 910 to $914 \mathrm{~cm}^{-1}$ after the addition of 2.5-10 phr of HNT. Further increase in the HNT loading has caused to increase in the peak intensities of $\mathrm{Si}-\mathrm{O}$ and $\mathrm{Al}-\mathrm{OH}$ vibrations. This limited intercalation of HNT throughout NR and other ingredients was evidently shown in XRD results. Moreover, the addition of HNT also results in shifting the decomposition temperature and char residue irrespective of the loadings of HNT, the tubular-shape and unique structure of HNT is clearly responsible to the thermal stability observed.
\end{abstract}

Keywords: halloysite nanotubes, natural rubber, Fourier-transform infrared, X-ray diffraction

\section{INTRODUCTION}

Nowadays, incorporation of a small amount of nano-fillers into the rubber matrix has drawn considerable attention during the last decade. ${ }^{1}$ Significant improvements of physical properties of rubber can be achieved through this 
technique. This improvement mainly depends on certain factors such as the aspect ratio, degree of dispersion, orientation of the filler. ${ }^{2}$ The use of Halloysite Nanotubes (HNT) into polymer matrix has been largely explored. HNT is unique and versatile nanomaterials that is formed by surface weathering of aluminosilicate minerals and is composed of aluminum, silicon, hydrogen and oxygen. . $^{3,4}$

Since HNT is chemically similar to clay, ${ }^{5}$ study on the role of HNT on the changes in functionalities and crystallinity of natural rubber (NR) are a keen challenge. The functionalities are generally monitored through infrared spectroscopy. It has been used to identify organic materials and analysis of complex mixtures. ${ }^{6}$ The advantages of infrared analysis lie in the facts that the spectrum of a molecule is a unique physical property which is not altered by any changes in which molecular identity is maintained. This is very similar to the X-ray diffraction (XRD) of the materials which is a rapid analytical technique primarily used for phase identification of a crystalline materials. ${ }^{7}$

In this study, we applied Fourier transform infrared (FTIR) and XRD studies to capture the change in functionalities and crystallinity of HNT filled NR. Furthermore, these results were correlated to the thermal stability of the composites. This study will lead to the scientific understanding on how HNT could influence the respective characteristics of the NR and extend to be source of useful information for manufacturing the rubber products based on NR/HNT composite. To the best of our knowledge, there is little study on the functionalities, crystallinity and thermal stability of NR/HNT composites. In this study, the corresponding composites were characterised through FTIR spectroscope, X-ray diffractometer and thermogravimetric analyser.

\section{EXPERIMENTAL DETAILS}

\section{$2.1 \quad$ Materials}

The NR used was 5L grade Standard Thai Rubber (STR 5L) which was purchased from Chalong Concentrated Natural Rubber Latex Industry Co. Ltd., Thailand. The HNT was supplied by Imerys Tableware Asia Limited, New Zealand. The compositions of HNT were mainly composed of $49.5 \%$ silicon dioxide $\left(\mathrm{SiO}_{2}\right)$, $35.5 \%$ aluminium oxide $\left(\mathrm{Al}_{2} \mathrm{O}_{3}\right), 0.29 \%$ ferum(III) oxide $\left(\mathrm{Fe}_{2} \mathrm{O}_{3}\right), 0.09 \%$ titanium dioxide $\left(\mathrm{TiO}_{2}\right)$ and the remaining trace content of calcium oxide $(\mathrm{CaO})$, magnesium oxide $(\mathrm{MgO})$, potassium oxide $\left(\mathrm{K}_{2} \mathrm{O}\right)$ and sodium oxide $\left(\mathrm{Na}_{2} \mathrm{O}\right)$, respectively. The stearic acid was purchased from Imperial Chemical Co. Ltd., Bangkok, Thailand. Zinc oxide $(\mathrm{ZnO})$ was obtained from Global Chemical Co. Ltd., Samut Prakarn, 
Thailand. N-cyclohexyl-2-benzothiazole sulfonamide (CBS) was purchased from Flexsys America L. P., West Virginia, USA and sulphur was purchased from Siam Chemical Co. Ltd., Samut Prakarn, Thailand.

\subsection{Preparation of NR/HNT Composites}

Table 1 shows the ingredients used for preparing NR/HNT composites. NR/HNT composites were prepared using the Brabender (Plastograph ${ }^{\circledR}$ EC Plus, Mixer W50EHT 3Z). The compounds were designated as H0, H2.5, H5, H7.5 and $\mathrm{H} 10$ for the composites at $0,2.5,5,7.5$ and $10 \mathrm{phr}$ of HNT, respectively. After dumping, the compounds were later passed through a tight nip $(\sim 2 \mathrm{~mm})$ on the Two Roll Mill to avoid an excess generated heat history. The compounds were then compression molded into the specific shapes by hydraulic-hot press with respect to the curing time observed from the moving die rheometer (MDR).

Table 1: Compound formulation of the NR/HNT composites.

\begin{tabular}{lccccc}
\hline \multirow{2}{*}{ Ingredients } & \multicolumn{5}{c}{ Sample code } \\
\cline { 2 - 6 } & H0 & H2.5 & H5 & H7.5 & H10 \\
\hline STR 5L & 100 & 100 & 100 & 100 & 100 \\
Stearic acid & 1 & 1 & 1 & 1 & 1 \\
Zinc oxide & 5 & 5 & 5 & 5 & 5 \\
HNT & 0 & 2.5 & 5 & 7.5 & 10 \\
CBS & 2 & 2 & 2 & 2 & 2 \\
Sulphur & 2 & 2 & 2 & 2 & 2 \\
\hline
\end{tabular}

Note: $S T R 5 L=5 L$ grade of standard Thai rubber; $C B S=N$-cyclohexyl-2-benzothiazole sulfonamide.

\subsection{Attenuated Total Reflection-Fourier Infrared Spectroscopy (ATR- FTIR)}

The FTIR spectra of NR/HNT composites were analysed using Bruker FTIR spectrometer (Tensor27) with a smart durable single bounce diamond, attenuated total reflection (ATR) cell. Each spectrum was recorded in a transmission mode and a number of scan to record IR spectra was 32 with a resolution of $4 \mathrm{~cm}^{-1}$ in the region range of 4,000 to $400 \mathrm{~cm}^{-1}$.

\section{$2.4 \quad$ XRD}

The XRD patterns of the samples were measured by a PHILIPS X'Pert MPD, using $\mathrm{CuK}_{\alpha}$ radiation tube $(\lambda=0.154 \mathrm{~nm})$ at $40 \mathrm{kV}$ and a current of $30 \mathrm{~mA}$. The diffraction pattern was scanned $(2 \theta)$ from $5^{\circ}-30^{\circ}$ along with step size 
(20) $0.05^{\circ}$ and $3^{\circ} \mathrm{min}^{-1}$ of scan speed. The d-spacing of layer particles was further calculated from Bragg's equation $(n \lambda=2 d \sin \theta)$, where $\lambda$ is the wavelength of the $\mathrm{X}$-ray, $d$ is the interlayer distance and $\theta$ is the angle of incident $\mathrm{X}$-ray radiation.

\subsection{Thermogravimetric Analysis (TGA)}

TGA at different loading of HNT was carried out with PerkinElmer, TGA2000. The sample was scanned from $30^{\circ} \mathrm{C}-600^{\circ} \mathrm{C}$ at the nitrogen air flow of $20 \mathrm{ml} \mathrm{min}-1$ with a heating rate of $5^{\circ} \mathrm{C} \mathrm{min}^{-1}$.

\section{RESULTS AND DISCUSSION}

\subsection{Attenuated Total Reflection-Fourier Infrared Spectroscopy (ATR- FTIR)}

Figure 1 represents the FTIR spectra in the wavenumber range of 4,000$400 \mathrm{~cm}^{-1}$ of pristine HNT, neat NR and NR containing 2.5, 5, 7.5 and $10 \mathrm{phr}$ of HNT. The observed bands, assignments and corresponding wavenumbers are tabulated in Table 2. For the pristine HNT (see Spectrum A), the adsorptions around 3,695 and $3,624 \mathrm{~cm}^{-1}$ are specifically assigned to the vibration of hydroxyl groups which are the stretching vibration of inner surface hydroxyl group. ${ }^{8,9}$ The presence of respective hydroxyl group has brought to absorption of moisture detected at the wavenumber of $3,315 \mathrm{~cm}^{-1}$. The distinct peak at $910 \mathrm{~cm}^{-1}$ is associated to the deformation of inner hydroxyl groups of $\mathrm{Al}-\mathrm{OH}$ librations, whereas, the peaks at 1,030 and $999 \mathrm{~cm}^{-1}$ are associated with stretching of Si-O. ${ }^{10}$

The infrared spectrum of the neat NR is assigned to Spectrum B. The characteristic peaks found at around 1,665, 1,445, 1,377 and $837 \mathrm{~cm}^{-1}$, were associated with stretching vibration of $\mathrm{C}=\mathrm{C}$ bond, bending vibration of $\mathrm{CH}_{2}$ and $\mathrm{CH}_{3}$ groups and out of plane deformation of $=\mathrm{C}-\mathrm{H}$ group, respectively. Upon inclusion of HNT (see Spectra C-F), there is a slight shift in spectrum of Si-O and Al-OH vibrations. The peak representing $\mathrm{Si}-\mathrm{O}$ bands shifted from 999 to 1,038 $\mathrm{cm}^{-1}$ and from 1,030 to $1,078 \mathrm{~cm}^{-1}$. Meanwhile, the band of $\mathrm{Al}-\mathrm{OH}$ vibration shifted from 910 to $914 \mathrm{~cm}^{-1}$ after the addition of $2.5-10 \mathrm{phr}$ of HNT. A little increase of these wavenumbers indicates higher frequency is used to vibrate such functionalities, it is thought to gain from the limited intercalation of HNT by NR and other ingredients as evidently shown in XRD results. Further increase in the HNT loading has caused to increase in the peak intensities of $\mathrm{Si}-\mathrm{O}$ and $\mathrm{Al}-\mathrm{OH}$ vibrations, confirming the presence of higher amount of HNT in the NR matrix. 


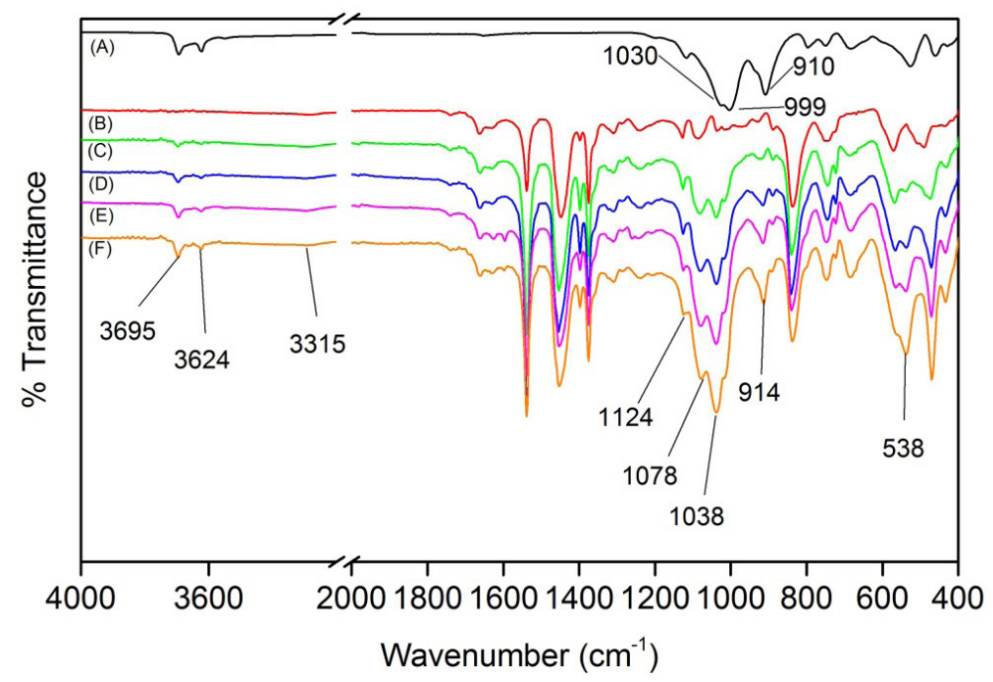

Figure 1: ATR-FTIR spectra of NR/HNT composites; (a) Pristine HNT, (b) H0, (c) H2.5, (d) H5, (e) H7.5 and (f) H10.

Table 2: ATR-FTIR assignments and corresponding wavenumber of NR/HNT composites.

\begin{tabular}{ll}
\hline Wavenumber $\left(\mathrm{cm}^{-1}\right)$ & Assignments \\
\hline 3,695 & OH stretching of inner-surface hydroxyl groups \\
3,624 & OH stretching of inner hydroxyl groups \\
3,292 & OH stretching of water \\
1,124 & Perpendicular Si-O stretching \\
$1,078-1,038$ & In-plane Si-O stretching \\
1,014 & OH deformation of inner-surface hydroxyl groups \\
914 & OH deformation of inner hydroxyl groups \\
800 & Symmetric stretching of Si-O \\
746 & Perpendicular Si-O stretching \\
685 & Perpendicular Si-O stretching \\
538 & Deformation of Al-O-Si \\
471 & Deformation of Si-O-Si \\
434 & Deformation of Si-O \\
\hline
\end{tabular}

\subsection{XRD}

Figure 2 shows the XRD pattern of pristine HNT, neat NR and NR containing 5 and $10 \mathrm{phr}$ of HNT. The $2 \theta$ values of refractive scattering and their relative $d$-spacing are tabulated in Table 3 . The peak at $12.13^{\circ}$ of pristine HNT 
corresponds to $d_{001}$ basal spacing of $7.29 \AA$ Á, determined by using Bragg's Law. This result indicates that the HNT was mainly in the dehydrated form and typically referred as $7 \AA$-Halloysite. Broader basal reflections obtained may be attributed to the small crystal size, the inconsistent layer spacing and the curvature of the layers. Two other peaks of the dehydrated state were also confirmed with the presence of $d_{020}, d_{110}$ and $d_{002}$ basal reflection at $19.98^{\circ}$ and $24.83^{\circ}$, which is equivalent to basal spacing of $4.44 \AA$ and $3.582 \AA$, respectively. It is clear that most of the peaks belonged to the 7 Á-Halloysite.

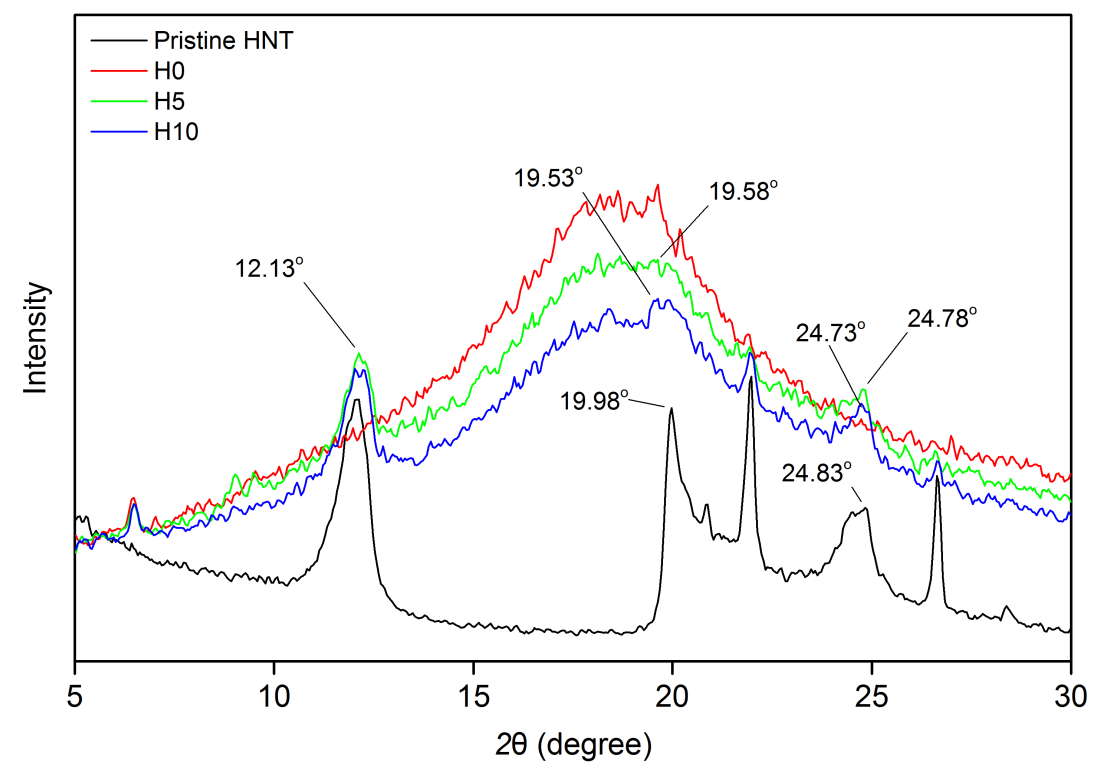

Figure 2: XRD patterns of pristine HNT and NR/HNT composites.

Table 3: Diffraction pattern characteristics of pristine HNT and NR/HNT composites.

\begin{tabular}{|c|c|c|c|c|c|c|}
\hline \multirow{3}{*}{$\begin{array}{l}\text { Sample } \\
\text { code }\end{array}$} & \multicolumn{6}{|c|}{ Specific plane and diffraction pattern } \\
\hline & \multicolumn{2}{|c|}{001 (7尺́-Halloysite) } & \multicolumn{2}{|c|}{ 020, 110 (7Á-Halloysite) } & \multicolumn{2}{|c|}{002 (7Á-Halloysite) } \\
\hline & $2 \theta$ & $d$-spacing $(\AA \dot{)})$ & $2 \theta$ & 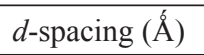 & $2 \theta$ & $d$-spacing $(\AA)$ \\
\hline $\begin{array}{l}\text { Pristine } \\
\text { HNT }\end{array}$ & 12.13 & 7.290 & 19.98 & 4.440 & 24.83 & 3.582 \\
\hline H5 & 12.13 & 7.290 & 19.58 & 4.530 & 24.78 & 3.590 \\
\hline $\mathrm{H} 10$ & 12.13 & 7.290 & 19.53 & 4.541 & 24.73 & 3.597 \\
\hline
\end{tabular}

Upon increased addition of HNT, the peak appeared at the same $2 \theta$ value for $d_{001}$ basal spacing of $7.29 \AA$. However, there are slight changes in the $d_{020}, d_{110}$ and $d_{002}$ basal spacing of $4.44 \AA$ and $3.582 \AA$. Such spacing was shifted to a lower 
$2 \theta$ equal to about $19.98^{\circ}-19.53^{\circ}$ and $24.83^{\circ}-24.73^{\circ}$ respectively. A little increase in HNT basal spacing indicates limited intercalation of HNT by NR and other ingredients. ${ }^{11}$ This intercalation of HNT was due to the non-polar characteristics of NR as well as the dehydrated form and small galleries of HNT. ${ }^{10}$

\section{$3.3 \quad$ TGA}

TGA measures the rate of change in the mass of a sample as a function of temperature or time in a controlled atmosphere. The measurement is used primarily to determine the thermal stability of materials as well as their compositional properties. The thermograms (TG) and derivative thermograms (DTG) of NR/HNT composites are shown in Figure 3(a) and 3(b), respectively. The decomposition temperatures at various weight losses and char residue are also summarised in Table 4. Here, the initial minor weight loss at around $180^{\circ} \mathrm{C}-250^{\circ} \mathrm{C}$ was owed to the presence of volatile materials such as stearic acid and absorbed water. ${ }^{12}$ Then, the drastic degradation of NR/HNT composites started at about $330^{\circ} \mathrm{C}$ and was completed at around $450^{\circ} \mathrm{C}$. This region is a common degradation region for NR segments that corresponded to peak observed of the DTG curve (see Figure $3[\mathrm{~b}]$ ). The degradation of NR segment is sensitive to the presence of the oxidised structure as well as the depletion of sulfidic crosslink in NR.

Notably, the HNT has greatly influenced the decomposition temperature at $10 \%, 50 \%$ and $70 \%$ weight loss of the NR/HNT composites. It was observed that the decomposition temperature clearly differed especially at the decomposition temperature over $50 \%$ of weight loss. Such improvement might be due to the entrapment of NR inside the lumen structure of the tubules ${ }^{13}$, interfacial and intertubular interactions between NR and HNT. Another probable reason can be attributed to the clay-like structure of HNT. With such nature, it can function as a thermal barrier that prevents heat transfer, slow down the vanishing of volatile matters during the degradation process. ${ }^{14}$ Further increase of HNT loading has given more char residue. Several reports proclaim that the amount of char or residual weight is very much dependent on the type and amount of filler. The difference in filler content mainly concerns char formation. ${ }^{15}$ 

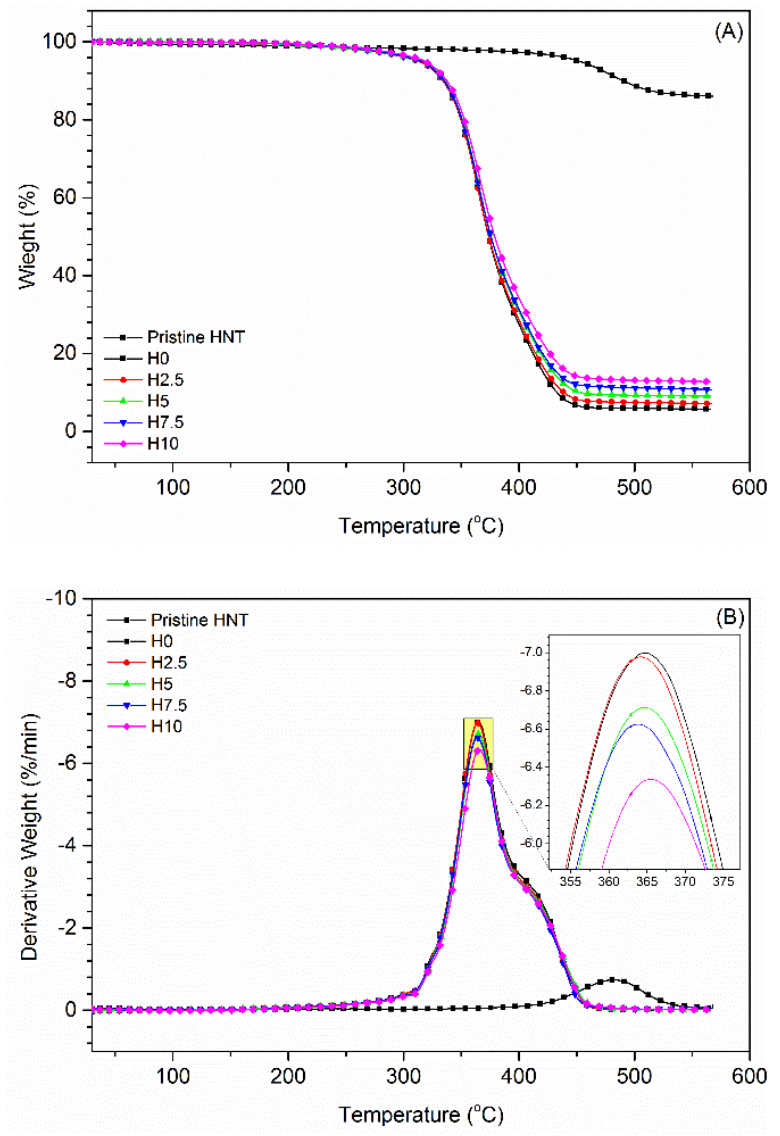

Figure 3: TG (a) and DTG (b) curves of NR/HNT composites.

Table 4: Temperature at $10 \%, 50 \%$ and $70 \%$ weight loss, maximum derivative weight and char formation of NR/HNT composites.

\begin{tabular}{lccccc}
\hline Sample & $\mathrm{T}_{10}\left({ }^{\circ} \mathrm{C}\right)$ & $\mathrm{T}_{50}\left({ }^{\circ} \mathrm{C}\right)$ & $\mathrm{T}_{70}\left({ }^{\circ} \mathrm{C}\right)$ & $\mathrm{DTG}_{\max }(\% / \min )$ & Char $(\%)$ \\
\hline H0 & 334 & 373 & 396 & 7.00 & 5.75 \\
H2.5 & 334 & 374 & 398 & 6.98 & 7.31 \\
H5 & 335 & 376 & 401 & 6.74 & 9.21 \\
H7.5 & 335 & 376 & 402 & 6.63 & 11.05 \\
H10 & 337 & 379 & 407 & 6.36 & 13.06 \\
\hline
\end{tabular}




\section{CONCLUSIONS}

NR/HNT composites were successfully prepared in this study. In this article, low loading of HNT was used as filler for NR composites. FTIR and XRD studies were used to capture the change in functionalities and crystallinity in association with the thermal stability of halloysite nanotubes filled NR. The band of Al-OH vibration shifted from 910 to $914 \mathrm{~cm}^{-1}$ after the addition of 2.5-10 phr of HNT. Further increase in the HNT loading has caused to increase in the peak intensities of $\mathrm{Si}-\mathrm{O}$ and $\mathrm{Al}-\mathrm{OH}$ vibrations. This limited intercalation of HNT throughout NR and other ingredients was evidently shown in XRD results. This intercalation of HNT was due to the non-polar characteristics of NR as well as the dehydrated form and small galleries of HNT. Moreover, the addition of HNT also results in shifting the decomposition temperature and char residue irrespective of the loadings of HNT, the tubular-shape and unique structure of HNT is clearly responsible to the thermal stability observed.

\section{ACKNOWLEDGEMENTS}

We gratefully acknowledge the Research and Development Office, Prince of Songkla University for supporting this project through the Grant No. SAT590594S.

\section{REFERENCES}

1. Rattanasom, N., Saowapark, T. \& Deeprasertkul, C. (2007). Reinforcement of natural rubber with silica/carbon black hybrid filler. Polym. Test., 26(3), 369-377, https://doi.org/10.1016/j.polymertesting.2006.12.003.

2. Lecouvet, B., Sclavons, M., Bourbigot, S. \& Bailly, C. (2013). Thermal and flammability properties of polyethersulfone/halloysite nanocomposites prepared by melt compounding. Polym. Degrad. Stab., 98(10), 19932004, https://doi.org/10.1016/j.polymdegradstab.2013.07.013.

3. Pasbakhsh, P., Ismail, H., Fauzi, M. N. A. \& Bakar, A. A. (2010). EPDM/ modified halloysite nanocomposites. Appl. Clay Sci., 48(3), 405-413, https://doi.org/10.1016/j.clay.2010.01.015.

4. Guo, B., Chen, F., Lei, Y., Liu, X., Wan, J. \& Jia, D. (2009). Styrenebutadiene rubber/halloysite nanotubes nanocomposites modified by sorbic acid. Appl. Surf. Sci., 255(16), 7329-7336, https://doi.org/10.1016/j. apsusc.2009.03.092. 
5. Joussein, E., Petit, S., Churchman, J., Theng, B., Righi, D. \& Delvaux, B. (2005). Halloysite clay minerals: A review. Clay Miner., 40(04), 383-426, https://doi.org/10.1180/0009855054040180.

6. Gunasekaran, S., Natarajan, R. K. \& Kala, A. (2007). FTIR spectra and mechanical strength analysis of some selected rubber derivatives. Spectrochim Acta A Mol. Biomol. Spectrosc., 68(2), 323-330, https://doi. org/10.1016/j.saa.2006.11.039.

7. Nayak, P. S. \& Singh, B. K. (2007). Instrumental characterization of clay by XRF, XRD and FTIR. Bull. Mater. Sci., 30(3), 235-238, https://doi. org/10.1007/s12034-007-0042-5.

8. Yuan, P., Tan, D. \& Annabi-Bergaya, F. (2015). Properties and applications of halloysite nanotubes: Recent research advances and future prospects. Appl. Clay Sci., 112-113, 75-93, https://doi.org/10.1016/j. clay.2015.05.001.

9. Du, M., Guo, B. \& Jia, D. (2010). Newly emerging applications of halloysite nanotubes: A review. Polym. Int., 59(5), 574-582, https://doi. org/10.1002/pi.2754.

10. Rooj, S., Das, A., Thakur, V., Mahaling, R. N., Bhowmick, A. K. \& Heinrich, G. (2010). Preparation and properties of natural nanocomposites based on natural rubber and naturally occurring halloysite nanotubes. Mater. Des., 31(4), 2151-2156, https://doi.org/10.1016/j.matdes.2009.11.009.

11. Senthivel, K., Manikandan, K. \& Prabu, B. (2015). Studies on the mechanical properties of carbon black/halloysite nanotube hybrid fillers in nitrile rubber nanocomposites. Mater. Today Proc., 2(4-5), 3627-3637, https://doi.org/10.1016/j.matpr.2015.07.118.

12. Ismail, H., Salleh, S. Z. \& Ahmad, Z. (2011). Curing characteristics, mechanical, thermal, and morphological properties of halloysite nanotubes (HNTs)-filled natural rubber nanocomposites. Polym. Plast. Technol. Eng., 50(7), 681-688, https://doi.org/10.1080/03602559.2010.551387.

13. Berahman, R., Raiati, M., Mazidi, M. M. \& Paran, S. M. R. (2016). Preparation and characterization of vulcanized silicone rubber/halloysite nanotube nanocomposites: Effect of matrix hardness and HNT content. Mater. Des., 104, 333-345, https://doi.org/10.1016/j.matdes.2016.04.099.

14. López-Manchado, M. A., Arroyo, M., Herrero, B. \& Biagiotti, J. (2003). Vulcanization kinetics of natural rubber-organoclay nanocomposites. J. Appl. Polym. Sci., 89(1), 1-15, https://doi.org/10.1002/app.12082.

15. Ismail, H. \& Shaari, S. M. (2010). Curing characteristics, tensile properties and morphology of palm ash/halloysite nanotubes/ethylene-propylenediene monomer (EPDM) hybrid composites. Polym. Test., 29(7), 872-878, https://doi.org/10.1016/j.polymertesting.2010.04.005. 